\title{
Effect of Meal Extracts on Retarding Lipid Oxidation in Refined Soybean Oil
}

\author{
Anjani* and Rajvir Singh \\ Department of Chemistry and Biochemistry, CCS Haryana Agricultural University, \\ Hisar-125004, Haryana, India \\ *Corresponding author
}

\begin{tabular}{l} 
Ke y w o r d s \\
$\begin{array}{l}\text { Carotenoids, Lipid } \\
\text { oxidation, Meal extracts, } \\
\text { Refined soybean oil and } \\
\text { total oxidation value }\end{array}$ \\
\hline Article Info \\
$\begin{array}{l}\text { Accepted: } \\
\text { 26 February } 2018 \\
\text { Available Online: } \\
\text { 10 March } 2018\end{array}$ \\
\hline
\end{tabular}

\section{A B S T R A C T}

The effectiveness of adding sesame and sunflower meal acetone extracts to stabilize refined soybean oil (RSO) was investigated for 120 days at $50{ }^{\circ} \mathrm{C}$. Sesame and sunflower meal acetone extracts were separately added at varying concentrations (500 ppm to $2000 \mathrm{ppm}$ ) to RSO. To compare their antioxidant activity, RSO was also supplemented with tertiary butylated hydroxy quinone (TBHQ) and propyl gallate (PG) at 200 ppm concentration. Control sample was also set-up that contained no additives. The conjugated dienes (CD), total oxidation value (TOTOX), thiobarbituric acid value (TBA), total tocopherol and carotenoids of RSO samples were monitored every 20 day using standard methods. Sesame and sunflower meal extracts at all concentrations were found to be more effective in stabilizing RSO against lipid oxidation than 200 ppm PG. TBHQ was most effective during storage period.

\section{Introduction}

Lipid oxidation is a broad term involving various types of reactions. It is necessary for physiological functions of human body implicating in both positive and negative way. It is uncontrolled oxidation initiated by free radicals and has side effects human health. These processes not only occur in human body but also occur in stored food, leading to formation of undesirable products and decrease the shelf-life of food. Oxidation of edible oils directly limits its quality, economic, flavor, safety and storage. Unsaturated fatty acids present in edible oils are susceptible to auto-oxidation and photooxidation during processing and storage (Choe and Min, 2006). Auto-oxidation mainly occurs in presence of oxygen resulting in formation of free radicals. It is initiated when hydrogen atom is abstracted in presence of initiators i.e. heat, light or oxygen and finally form lipid radical. It reacts with oxygen and form lipid peroxide radical. These are very unstable and readily converted into hydroperoxides. On the other hand, photo-oxidation occurs when 
triplet oxygen is converted into singlet oxygen when come in contact with UV rays. Polyunsaturated fatty acids present in oils reacts with singlet oxygen and form hydroperoxides. Free radicals can be inhibited by compound called antioxidants and remove free radicals from food. Recently natural antioxidants are preferred over synthetic because they are safe and healthy since they are present in plants and plant foods.

Sesame (Sesamum indicum L.) is an important source of edible oil because of its high content of lipid (Shyu and Hwang, 2002). Lignan along with tocopherol contribute to their higher stability against oxidation as compared to other vegetable oils (Gertz et al., 2000). It is not only good source of edible oil but also widely used in baked goods and confectionery products (Namiki, 1995). The oil shows remarkable stability despite of high unsaturation. Kang et al., 1999 studied the health-promoting effects of sesame. It shows a hypocholesterolemic effect, suppressive effect on chemically induced cancer and anti-aging properties. Sesame seed meal is a by-product of sesame oil industry and used as poultry feed. Studies shows that a significant amount of antioxidant compounds still exist in sesame meal (Mohdaly et al., 2011; Shahidi et al., 2006; Hamed et al., 2012).

Sunflower (Helianthus annus L.) is the second largest oilseed crop. It has been the main source of edible vegetable oil in Russia and other eastern European countries for decades. Sunflower is most popular vegetable oil preferred over soybean, cottonseed and palm oils in many countries. Because of its high content of protein, sunflower meal is used primarily in ruminant feed, but its nutritional, sensory and functional properties also make a great interest for human food as a protein source (Sodini and Canella, 1977). Sunflower meal is also rich in minerals, vitamins $\mathrm{A}$ and E, phenolic acids, polyphenols, flavonoids and condensed tannins and studied as a potential source of cheap natural antioxidants (Kreps et al., 2014). Free radicals formed during propagation step of oil oxidation are neutralized by hydrogen atom donated by antioxidants. So, they could be added to oils, fat and foods to prevent rancidity, offflavouring and toxic compounds resulting from oxidation.

In this study, sesame (Sesamum indicum L.) and sunflower (Helianthus annus L.) seed meals are studied as potential antioxidant agents to improve the shelf-life of oils.

\section{Experimental}

\section{Materials}

The seeds of soybean, sesame and sunflower were collected from the farmer's field. These seeds were cleaned manually, to remove stones, damaged and immature seeds. After cleaning, the seeds were ground into fine powder. The seed oil of soybean was extracted as well as refined and studied for their various chemical parameters. The dried defatted seed meal of sunflower and sesame were extracted with acetone and further used as antioxidants.

\section{Extracts preparation}

Sesame and sunflower meals were dried and ground into a fine powder in an electric grinder. One hundred grams of samples were defatted with hexane $(3$ times $\times 500 \mathrm{ml})$ at room temperature. The defatted residue was washed with distill water $(3$ times $\times 500 \mathrm{ml}$ ) and dried at $50{ }^{\circ} \mathrm{C}$. Ten grams of above obtained residue was extracted with acetone $(150 \mathrm{ml})$ by Soxhlet method for $8 \mathrm{~h}$. Extracts were filtered, solvent removed (in a rotary evaporator below $40{ }^{\circ} \mathrm{C}$ ), weighed and residue was redissolved in acetone $(100 \mathrm{ml})$ to give a solution of known concentration. It was stored in refrigerator until further use. 


\section{Oil extraction}

Oil was extracted by Soxhlet method using petroleum ether $\left(60-80{ }^{\circ} \mathrm{C}\right)$ for $8 \mathrm{~h}$. Solvent extraction processes include basically three steps: preparation, extraction, and desolventizing.

\section{Refining of oil}

Refining of oils was done by chemical method (Carr, 1976) in the following steps: Degumming, neutralization, bleaching and deodorizing.

\section{Storage of oil samples}

RSO samples supplemented with TBHQ 200 ppm, PG $200 \mathrm{ppm}$, sesame and sunflower meal at concentrations $(500,1000$ and 2000 ppm) were incubated at $50{ }^{\circ} \mathrm{C}$ for 120 days to study oxidative stability.

Control sample also incubated that contained no additives. Samples were stored in uniform glass beaker wrapped with aluminium foil and each container was appropriately labelled.

Required quantity of the oils were withdrawn at day 20,40, 60, 80, 100 and 120 and studied for the oxidative quality indices.

\section{Analytical procedures}

\section{Conjugated dienes}

Conjugated dienes was assessed based on IUPAC method (1987).

\section{Total oxidation values}

Total oxidation values of oil samples were determined using the following equation according to Shahidi and Wanasundara, 2008:

Total oxidation values $=2 \times \mathrm{PV}+\mathrm{AV}$

\section{Thiobarbituric acid value}

Thiobarbituric acid value was determined according to the method of Johansson and Marcuse, 1973.

\section{Total tocopherol}

Total tocopherol was determined by the method of Philip et al., (1954).

\section{Carotenoids}

Carotenoids content was evaluated by the method of Vasconcellous et al., (1980).

\section{Results and Discussion}

Effects of additives on conjugated dienes (CD) of refined soybean oil

Table 1 depicts changes in conjugated dienes of RSO stored with varying concentrations of sesame and sunflower meal extracts as well as 200 ppm TBHQ and PG. It was observed that the addition of sesame and sunflower meal extracts did decrease the CD formation. Sesame meal extract at all concentrations is more effective than PG 200 ppm while in sunflower meal extracts only 1000 and 2000 ppm concentrations are more effective and $500 \mathrm{ppm}$ was less effective. Thus, effect of varying concentrations of sesame meal extract was more pronounced than the effect of varying concentrations of sunflower meal extracts as shown in table. However, TBHQ was most effective antioxidant during preservation of RSO.

\section{Effects of additives on total oxidation values (TOTOX) of refined soybean oil}

Figure 1 depicts variations of TOTOX values of RSO stored with sesame and sunflower meal extracts as well as $200 \mathrm{ppm}$ TBHQ and PG. The trend observed in graph showed that 
TOTOX values gradually increase with storage period. Initial TOTOX value was $6.74 \pm 0.13$. The maximum increase of TOTOX was observed in control sample with no additives $(902.07 \pm 18.94)$.

TBHQ has maximum stabilization effect with minimum increase in TOTOX i.e. $583.48 \pm 11.83$. Under accelerated storage of 120 days, the increase of TOTOX value was in following sequence in ascending order:

TBHQ 200 ppm $(583.48 \pm 11.83)<$ sesame meals extract $2000 \mathrm{ppm}(636.59 \pm 15.91)<$ sunflower meals extract 2000 ppm $(670.34 \pm 16.75)<$ sesame meals extract 1000 ppm $(682.2 \pm 14.32)<$ sunflower meals extract $1000 \mathrm{ppm}(700.97 \pm 15.96)<$ sesame meals extract $500 \mathrm{ppm}(708.12 \pm 15.99)<$ sunflower meals extract 500 ppm $(726.45 \pm 14.34)<$ PG 200 ppm $(771.48 \pm 15.83)<$ control $(902.07 \pm 18.94)$, respectively, after 120 days.
Effects of additives on thiobarbituric acid value of refined soybean oil

Figure 2 depicts variations of TBA values of RSO stored with sesame and sunflower meal extracts as well as $200 \mathrm{ppm}$ TBHQ and PG. TBA values gradually increase with storage period. The TBA value of control RSO sample increased from $9.3 \pm 0.06$ to $172.55 \pm 0.6$ which is significantly higher than those of the other samples containing sesame meal extracts (500, $1000,2000 \mathrm{ppm})$; sunflower meal extracts (500, 1000, $2000 \mathrm{ppm})$; PG (200 ppm) and TBHQ (200 ppm). RSO samples treated with TBHQ (200 ppm), PG (200 ppm), sesame meal extracts (500, 1000 and $2000 \mathrm{ppm}$ ), sunflower meal extracts $(500,1000$ and 2000 $\mathrm{ppm}$ ) has following TBA values $122.37 \pm 2.48$, $152.97 \pm 3.14, \quad 145.12 \pm 2.86, \quad 137.57 \pm 2.72$, $138.42 \pm 2.69,156.49 \pm 3.45,150.91 \pm 3.29$ and $153.52 \pm 3.78$, respectively, on $120^{\text {th }}$ day of storage.

Fig.1 Change in total oxidation values of refined soybean oil stored with varying concentration of sesame and sunflower meal extracts as well as 200 ppm TBHQ and

\section{PG over a period of 120 days}

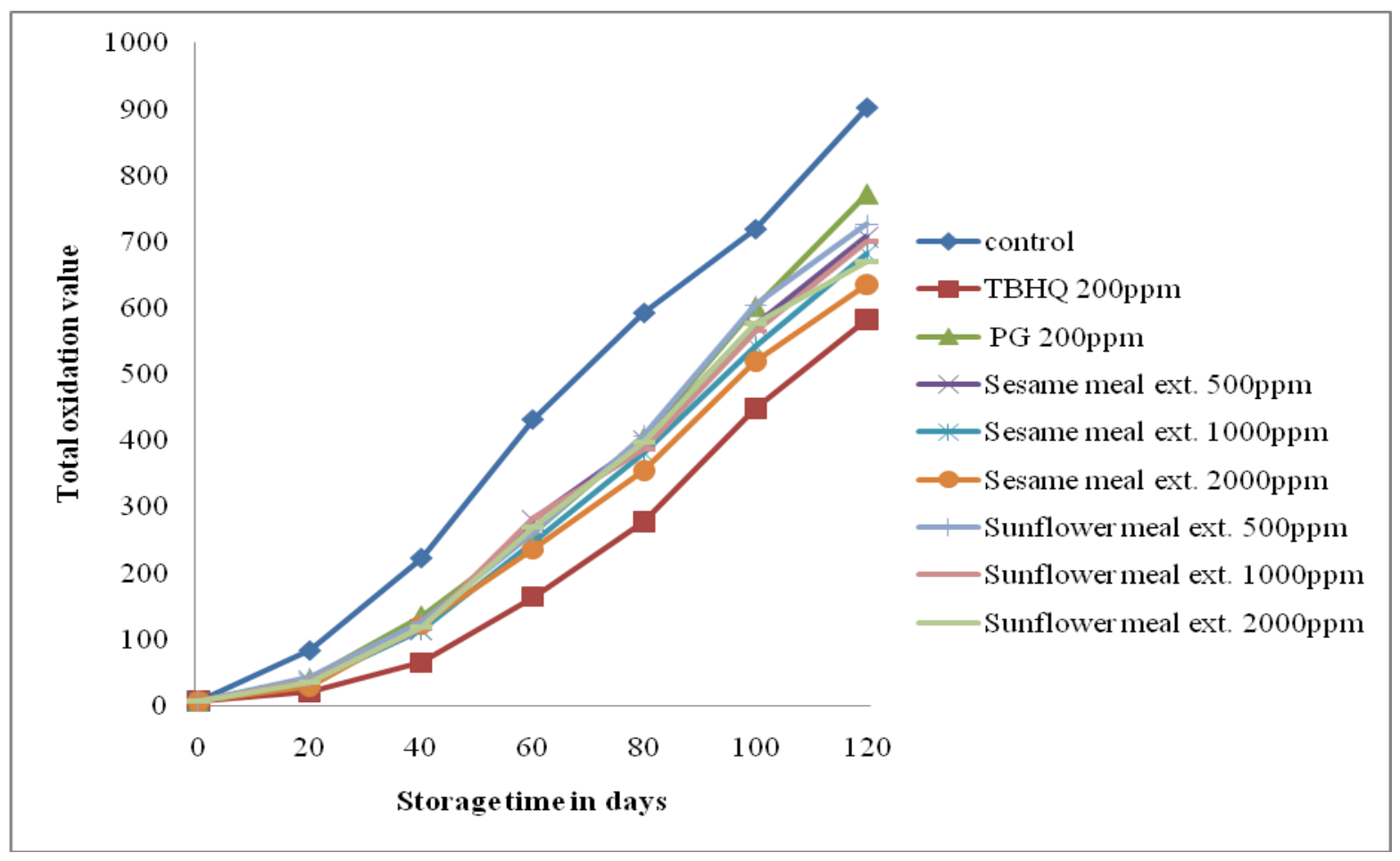


Fig.2 Change in thiobarbituric acid values of refined soybean oil stored with varying concentration of sesame and sunflower meal extracts as well as 200 ppm TBHQ and

PG over a period of 120 days

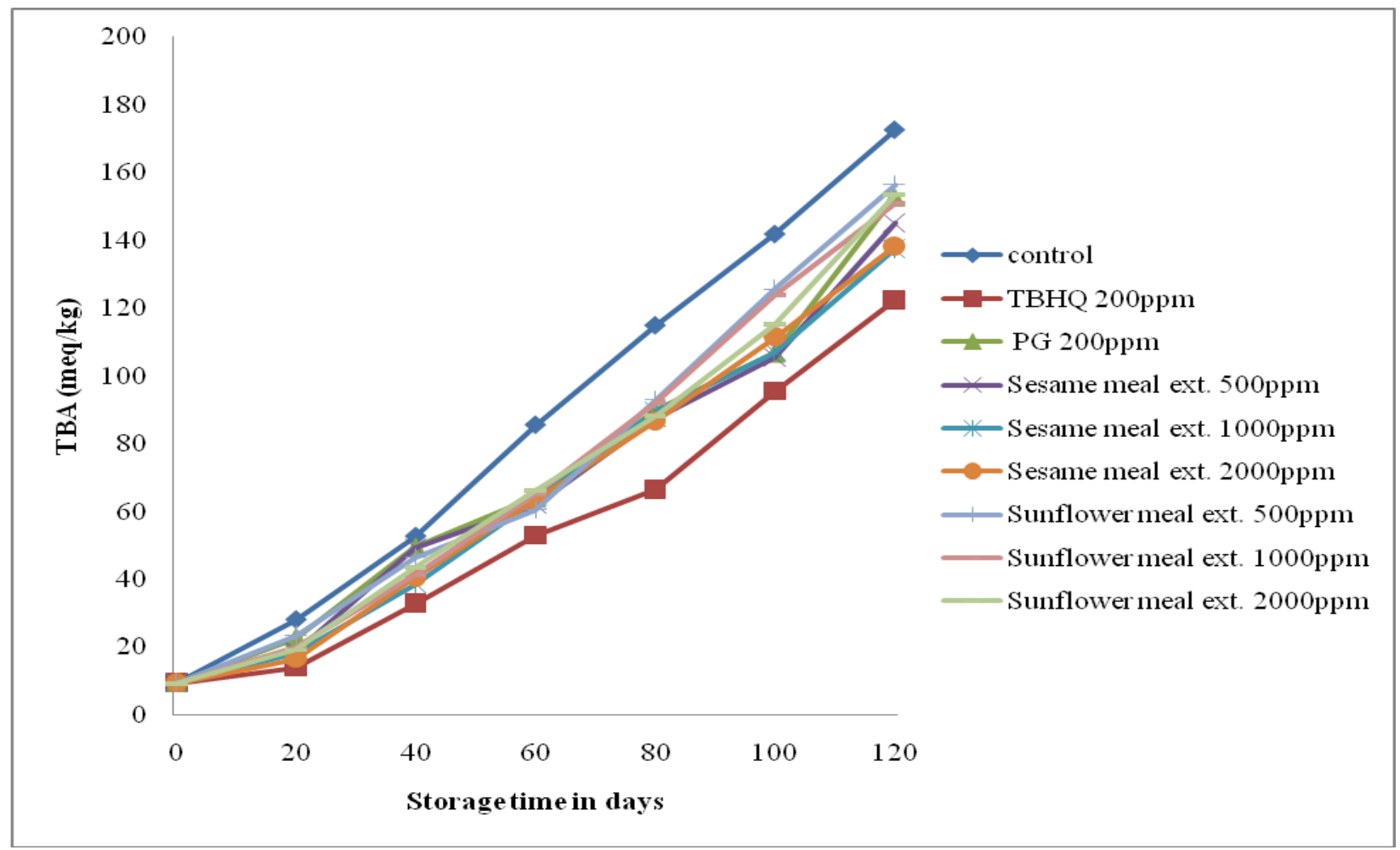

Fig.3 Change in total tocopherol of refined soybean oil stored with varying concentration of sesame and sunflower meal extracts as well as 200 ppm TBHQ and PG over a period of 120 days

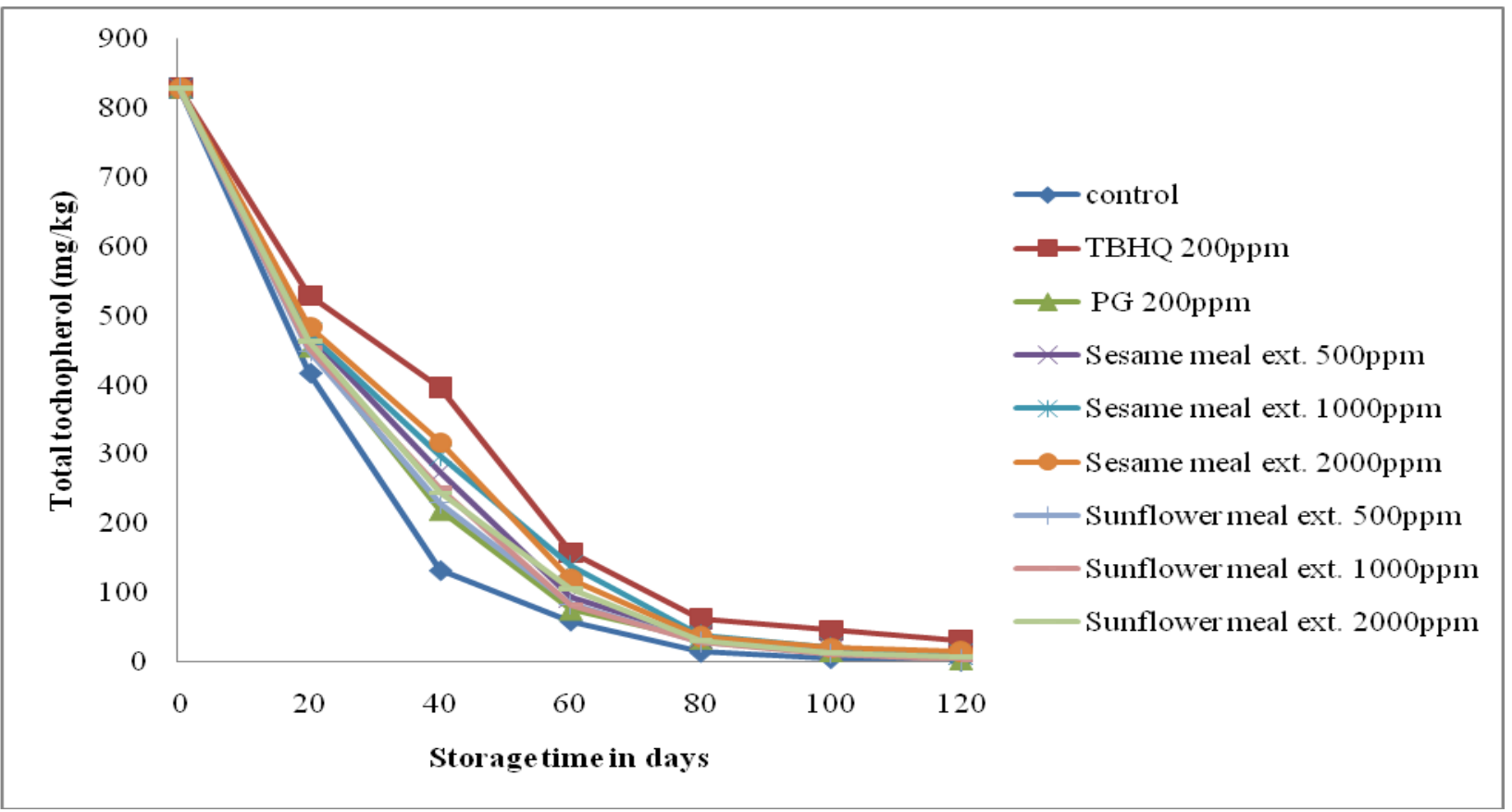


Fig.4 Change in carotenoids contents of refined soybean oil stored with varying concentration of sesame and sunflower meal extracts as well as 200 ppm TBHQ and PG over a period of 120 days

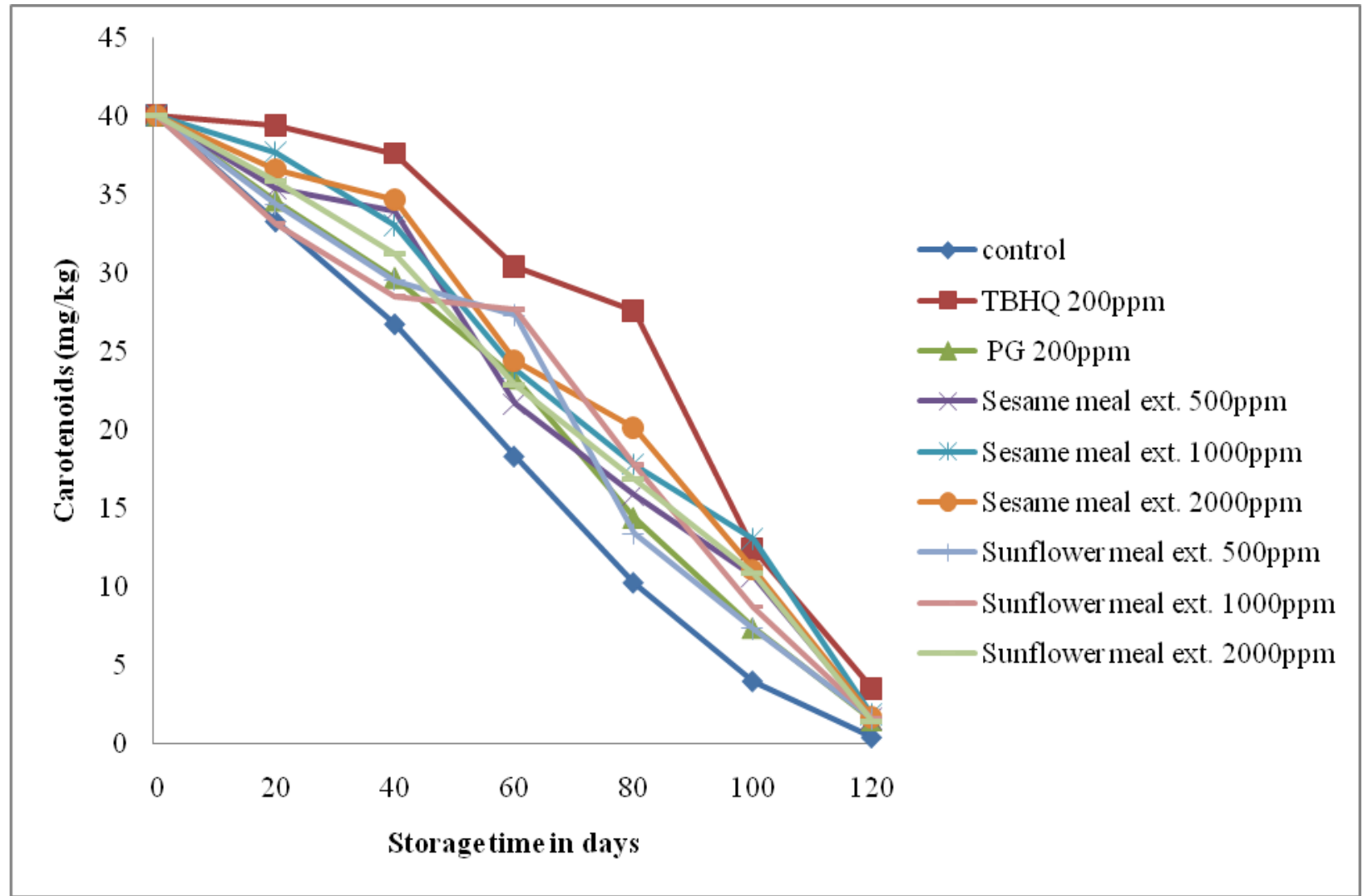

Table.1 Change in conjugated dienes (\% as dienoic acid) of refined soybean oil stored with varying concentration of sesame and sunflower meal extracts as well as 200 ppm TBHQ and PG over a period of 120 days

\begin{tabular}{|c|c|c|c|c|c|c|c|}
\hline \multirow[t]{2}{*}{ Sample } & \multicolumn{7}{|c|}{ Storage period (days) } \\
\hline & $\mathbf{0}$ & 20 & 40 & 60 & 80 & 100 & 120 \\
\hline Control & $1.2 \pm 0.03$ & $7.9 \pm 0.18$ & $15.23 \pm 0.38$ & $20.55 \pm 0.43$ & $28.53 \pm 0.62$ & $40.07 \pm 0.92$ & $52.55 \pm 1.31$ \\
\hline TBHQ (200 ppm) & $1.2 \pm 0.03$ & $4.8 \pm 0.11$ & $6.1 \pm 0.15$ & $11.37 \pm 0.26$ & $15.68 \pm 0.32$ & $21.35 \pm 0.51$ & $36.22 \pm 0.76$ \\
\hline PG (200 ppm) & $1.2 \pm 0.03$ & $6.3 \pm 0.14$ & $9.09 \pm 0.19$ & $18.97 \pm 0.39$ & $23.53 \pm 0.63$ & $36.67 \pm 0.88$ & $46.88 \pm 1.12$ \\
\hline $\begin{array}{l}\text { Sesame meal extract } \\
(500 \mathrm{ppm})\end{array}$ & $1.2 \pm 0.03$ & $5.8 \pm 0.12$ & $10.88 \pm 0.22$ & $14.12 \pm 0.35$ & $18.88 \pm 0.43$ & $28.41 \pm 0.71$ & $41.34 \pm 0.99$ \\
\hline $\begin{array}{l}\text { Sesame meal extract } \\
(1000 \mathrm{ppm})\end{array}$ & $1.2 \pm 0.03$ & $6.2 \pm 0.13$ & $8.07 \pm 0.16$ & $14.57 \pm 0.34$ & $21.27 \pm 0.48$ & $36.21 \pm 0.76$ & $45.15 \pm 1.08$ \\
\hline $\begin{array}{l}\text { Sesame meal extract } \\
(2000 \mathrm{ppm})\end{array}$ & $1.2 \pm 0.03$ & $5.8 \pm 0.13$ & $8.47 \pm 0.19$ & $15.42 \pm 0.37$ & $17.39 \pm 0.41$ & $30.29 \pm 0.69$ & $39.73 \pm 0.91$ \\
\hline $\begin{array}{l}\text { Sunflower meal extract } \\
(500 \text { ppm) }\end{array}$ & $1.2 \pm 0.03$ & $6 \pm 0.13$ & $8.88 \pm 0.2$ & $16.49 \pm 0.36$ & $26.69 \pm 0.69$ & $29.87 \pm 0.65$ & $47.59 \pm 1.09$ \\
\hline $\begin{array}{l}\text { Sunflower meal extract } \\
(1000 \text { ppm) }\end{array}$ & $1.2 \pm 0.03$ & $6 \pm 0.15$ & $9.09 \pm 0.21$ & $17.91 \pm 0.44$ & $20.66 \pm 0.47$ & $32.87 \pm 0.75$ & $44.23 \pm 0.92$ \\
\hline $\begin{array}{l}\text { Sunflower meal extract } \\
(2000 \mathrm{ppm})\end{array}$ & $1.2 \pm 0.03$ & $6.4 \pm 0.15$ & $9.97 \pm 0.18$ & $16.52 \pm 0.34$ & $20.13 \pm 0.42$ & $34.43 \pm 0.75$ & $44.16 \pm 0.97$ \\
\hline
\end{tabular}


Effects of additives on total tocopherol of refined soybean oil

The degradation of total tocopherol for RSO samples stabilized with the extract, TBHQ, PG and control is depicted in figure 3. It was clearly observed that all the varying concentrations of sesame and sunflower extracts were effective. The capability of these extracts to reduce the degradation of tocopherol of RSO slightly increased as the concentration of the extract increased. It was found sesame meal extract is more stable than sunflower meal extract. Throughout the 120 days of storage, the tocopherol of RSO control sample that contained no additive was lower than oil samples that contained additives (extracts, PG and TBHQ). As the concentration of sesame and sunflower extracts increased in the oil sample, the degradation of tocopherol remarkably decreased. During storage TBHQ was most effective in preservation of oil. Difference in antioxidant activity of different antioxidants may be due to chemical structures.

\section{Effects of additives on Carotenoids of refined soybean oil}

The extent of changes in the carotenoid content of RSO subjected to $50^{\circ} \mathrm{C}$ during storage period of 120 days is illustrated in figure 4. It was noted that the carotenoid content of the RSO samples decreased at higher rate. After the completion of the storage period of 120 days, the level of carotenoid for the control RSO samples reached to $0.34 \mathrm{mg} / \mathrm{kg}$. All the additives lowered the deterioration of carotenoid in RSO samples at varying degrees. The rate of deterioration of carotenoid was slightly lower among treated samples as compared to the control. The degradation of carotenoid of oil samples decreased gradually as the concentration of sesame and sunflower extracts increased from $500 \mathrm{ppm}$ to 2000 ppm. Sesame and sunflower meal extracts at all varying concentrations were more effective in preservation of RSO than 200 ppm PG. Although sesame meal extract is superior to sunflower meal extract at all concentrations.

The additions of sesame and sunflower meal extracts to refined soybean oil have remarkable effect on retardation on lipid oxidation. Meal extracts had better antioxidant efficacy than $200 \mathrm{ppm}$ propyl gallate. However, sesame extracts was superior to sunflower extracts in controlling oxidation process.

\section{Acknowledgement}

The author is grateful to University Grants Commission, New Delhi, India for awarding junior research fellowship.

\section{References}

Carr, R. A. 1976. Refining and degumming system for edible fats and oils. Journal of the American Oil Chemist's Society. 55: 766-770.

Choe, E., and Min, D. B. 2006. Mechanisms and factors for edible oil oxidation. Comprehensive Reviews in Food Science and Food Safety. 5:169-86.

Gertz, C., Klostermann, S. and Kochhar, S. P. 2000. Testing and Comparing Oxidative Stability of Vegetable Oils and Fats at Frying Temperature. European Journal of Lipid Science and Technology. 102: 543-551.

Hamed, S. F., Wagdy S. M. and Megahed M. G. 2012. Chemical Characteristics and Antioxidant Capacity of Egyptian and Chinese Sunflower Seeds: A Case Study. Life Science Journal. 9(2): 320328.

International Union of Pure and Applied Chemistry 1987. Standard methods for 
the analysis of oils, fat and derivatives. 7th Edition, London: Blackwell Scientific.

Johansson, L. and Marcuse, R. 1973. Studies on the TBA test for rancidity grading: II. TBA reactivity of different aldehyde classes. Journal of American Oil Chemist's Society. 50: 387-391.

Kang, M. H., Kawai, Y., Naito, M., and Osawa, T. 1999. Dietary defatted sesame flour decreases susceptibility to oxidative stress in hypercholesterolemic Rabbits. Journal of Nutrition. 129: 1885-1890.

Kreps, F., Vrbiková, L. and Schmidt, S. 2014. Industrial Rapeseed and Sunflower Meal as Source of Antioxidants. International Journal of Engineering Research and Applications. 4(2): 45-54.

Mohdaly, A. A.A., Smetanska, I., Ramadan, M. F., Sarhan, M. A. and Mahmoud, A. 2011. Antioxidant potential of sesame (Sesamum indicum) cake extract in stabilization of sunflower and soybean oils. Industrial Crops and Products. 34: 952- 959 .

Namiki, M. 1995. The chemistry and physiological functions of sesame. Food Reviews International. 11: 281-329.

Philip, B., Bernard, L. and William, H. 1954. Vitamins and Deficiency Diseases, In:
Practical Physiological Chemistry, McGraw-Hill company, INC. New York, Toronto, London, 1272-1274.

Shahidi, F. and Wanasundara, U. N. 2008. Methods for measuring oxidative stability in edible oils. In Akoh, C.C. and Min D.B. (Eds). Food Lipids: Chemistry, Nutrition and Biotechnology, p. 387-388. New York: CRC Press.

Shahidi, F., Chandrica, M., Liyana, P. and Dana, S. W. 2006. Antioxidant activity of white and black sesame seeds and their hull fractions. Food Chemistry. 99: $478-483$.

Shyu, Y. S. and Hwang, S. L. 2002. Antioxidative activity of the crude extract of lignan glycosides from unfrosted Bruma black sesame meal. Food Research International. 35: 357365.

Sodini, G. and Canella, M. 1977. Acid butanol removal of color forming phenols from sunflower meal. Journal of Agricultural and Food Chemistry. 25: $822-825$.

Vasconcellous, J. A., Berry, J. W. and Weber, C. W. 1980. The properties of Cucurbita foetidissima seed oil. Journal of American Oil Chemist's Society. 57: $310-313$.

\section{How to cite this article:}

Anjani and Rajvir Singh. 2018. Effect of Meal Extracts on Retarding Lipid Oxidation in Refined Soybean Oil. Int.J.Curr.Microbiol.App.Sci. 7(03): 3468-3475. doi: https://doi.org/10.20546/ijcmas.2018.703.398 